\title{
Competition, cooperation and human flourishing: commentary on Koch
}

\section{Hazem Zohny}

Mainstream bioethics takes after a competitive, individualistic understanding of biology and is ultimately rooted in libertarian 19th-century values. These in turn drive much of the enthusiasm for transhumanism and explain why disability in bioethics is often characterised as a lamentable deficiency.

That, at least, is the concern raised by Tom Koch in his paper Disabling disability amid competing ideologies. 1 He contrasts this paradigm with a cooperative, communal understanding of biology, and in turn, of bioethics-one which entails generally prioritising a socially cooperative and accommodating response to the fact that different humans have different capacities.

It is tempting to defensively nit-pick Koch's criticisms; to conservatively argue that bioethics is fine as it is, thank you very much. That would be the wrong response, I think. His paper raises a crucial and often neglected issue, which is how the notion of human flourishing is implicitly characterised in these discussions. Nevertheless, I think there is a false dichotomy at the heart of this paper-one between the individualistic/competitive and the communal/cooperative-which overestimates the level of disagreement in bioethics.

Koch argues that at least some of the elements of a Darwinian competition have been smuggled into bioethics as unquestioned suppositions that inform much of the domain's values. These propel the view of disability as unfortunate deviations that require fixing or eliminating, with enhancement being held as an individual-centred project bent on creating the ultimate competitor. A better bioethics would forgo such suppositions and replace them with the cooperative and communal spirit that Kropotkin first noted in the animal kingdom.

But is it true that trying to biomedically 'fix' impairments reflects an individualistic, competitive approach to difference, while trying to communally accommodate difference reflects a more cooperative one? I don't think so.

On the one hand, a society that decides to, say, ensure that most of its buildings, bathrooms and transports systems have wheelchair access does indeed reflect a communal, cooperative response to the fact that some individuals are unable to walk. But consider what is required to develop interventions that alleviate conditions that hinder the ability to walk. Typically, modern biomedical advancements require hundreds of thousands of researchers to cooperate across international groups, building on the work of their predecessors, all in a collaborative endeavour to come up with such interventions. Much of that research is funded through grants that are paid for by taxes collected from millions of other people. And, if an effective intervention is developed, many societies respond by making it affordable to most through more public funds.

That is to say, this process of trying to directly ameliorate impairments - while by no means a perfect process - in fact reflects a highly cooperative and communal effort that effectively involves millions of people working together. True, they might not all be working together consciously or even for altruistic reasons, but neither is universal conscious cooperation or individual altruism necessarily driving wheelchair access or any other societal accommodation of differently abled individuals.

To an extent, Koch appears to agree that these two approaches are not entirely separable, and indeed concludes that the accommodating response 'accepts individualistic competition as natural and healthy' but 'permits all to compete together as equal social members'. But if this is true, it 
suggests that the issue here is not so much two rival ideologies rooted in competition or cooperation, but different visions of what human flourishing entails.

And it is this issue that I think is at the heart of much of the disagreement: namely, what assumptions do we make about the relationship between our capacities and their impact on our chances of leading good lives? It may well be true, as Koch argues, that merely having a high IQ tells us little about one's chances of reporting happiness or satisfaction with one's life, while many impairments do nothing to get in the way of reporting that one is happy and satisfied.

One explanation for this may relate to our capacity for hedonic adaptation: people generally tend to revert to their baseline level of reported happiness and satisfaction even after overwhelming tragedy or fortune.2 More generally, our propensity to perceive our lives as ultimately worthwhile is highly resilient to adversity. 3

As such, perhaps for 'critics of difference', as Koch describes them, they lament disability not because it necessarily reduces reported well-being, but because it can limit one's possible life plans in some way or other-something Koch readily concedes (the blind can't fly planes). In turn, for proponents of enhancement, there may be an assumption that greater capacities tend to enable more life opportunities, and having more of those is good for well-being in some objective sensethat is, regardless of how they impact our sense of happiness or satisfaction.

The point here is that these assumptions about what constitutes a good life are often implicit and vague in this discussion. Becoming clearer about what well-being, flourishing or the good life refer to can help explain much of the disagreement.

And this is where I think the welfarist account, which Koch raises but quickly dismisses, is especially useful. Koch correctly points out that the welfarist account of disability excludes prejudice-which I argue is an amendable mistake by the architects of the account. 4 But even without amending it, the welfarist account by no means fails to take into consideration the context in which differences become disadvantages: in fact, it is only in conjunction with one's circumstances-be they personal, social, political or physical-that a bodily or mental state can be disabling (or enhancing) in the welfarist sense.

But more than its emphasis on context, the welfarist account makes no use of concepts like 'normal' functioning or 'abnormal' functioning. Normality, whatever it is, is irrelevant here. Instead, the focus is on leading a good life irrespective of normality, and in that way the account compels us to keep revisiting and reanalysing that age-old question central to this discussion: what is a good life? And more specifically, how do our bodies and minds, in conjunction with our particular circumstances, impact our likelihood of having one.

\section{References}

1 Koch T. Disabling disability amid competing ideologies. J Med Ethics 2018;44:575-9.

2 Brickman P, Coates D, Janoff-Bulman R. Lottery winners and accident victims: is happiness relative? J Pers Soc Psychol 1978;36:917-27.

3 Bonanno GA. Loss, trauma, and human resilience: have we underestimated the human capacity to thrive after extremely aversive events? Am Psychol 2004;59:20-8. 
4 Zohny $\mathrm{H}$. Enhancement, disability and the riddle of the relevant circumstances. J Med Ethics 2016;42:605-10. 